UDC 613.6.027: 613.63: 613.65: 616-084

DOI: $10.21668 /$ health.risk/2019.3.12.eng

\title{
OXIDATIVE STRESS AND ANTIOXIDANT PROTECTION IN PEOPLE OF VARIOUS AGE UNDER CONTACT WITH ADVERSE OCCUPATIONAL FACTORS
}

\author{
I.A. Umnyagina, T.V. Blinova, L.A. Strakhova, V.V. Troshin, S.A. Kolesov, O.V. Sherstobitova \\ Nizhegorodskiy Scientific Research Institute for Hygiene and Occupational Pathology, 20 Semashko Str., \\ Nizhniy Novgorod, 603950, Russian Federation
}

Free radical oxidation and antioxidant protection system has been examined for decades. However, experts still haven't been able to determine cause-and-effect relations between oxidative stress, age, working conditions, and a risk of functional and organic disorders that can develop in a human body.

Our research goal was to detect peculiarities related to age dynamics of integral parameters that describe oxidative stress and total antioxidant capacity of blood serum; to assess their changes depending on impacts exerted by adverse occupational factors on a worker's body.

244 people aged from 18 to 65 were under observation; they all had physical loads at their workplaces and contacted adverse chemicals. These people underwent regular medical check-ups at a consultancy polyclinic of the Rospotrebnadzor's Nizhniy Novgorod Scientific Research Institute for Hygiene and Occupational Pathology.

The first stage in the research involved mass screening aimed at detecting parameters related to oxidative stress and total antioxidant capacity of blood serum in all the examined people. At the second stage in research we analyzed levels of oxidative stress and total antioxidant capacity of blood serum taking into account age of an examined person and impacts exerted by adverse occupational factors $(n=174)$.

Integral parameters of oxidative stress and total antioxidant capacity of blood serum were determined with a calorimetric biochemical microplate procedure.

We detected that oxidative stress grew with age and antioxidant protection dropped. It was shown that adverse chemical factors exerted more apparent impacts on oxidative stress and antioxidant capacity of blood serum on people from the same age group than physical loads. We determined integral parameters of oxidative stress and antioxidant capacity of blood serum in people from various age groups and limits of their age-dependent changes. These parameters can serve as informative tests for monitoring over health, assessing gravity of a disease, its forecast, treatment efficiency, and preventive activities.

Key words: oxidative stress, total antioxidant capacity of blood serum, age, physical overloads, chemical factors.

For many years, researchers have been focusing on free radical oxidation processes. Multiple research results prove there is a tight correlation between oxidative stress (OS) and anti-oxidant protection and various diseases, functional disorders, and psycho-emotional state of a body [1-4]. Adverse occupational factors (physical, chemical, and psychophysiological ones) also make for disorders in balanced functioning of oxidant and anti-oxidant systems [5, 6]. Latest research confirms a hypothesis that OS makes a significant contribution into pathogenesis of ageing. Free radical or "oxidation theory of ageing" states that a

(c) Umnyagina I.A., Blinova T.V., Strakhova L.A., Troshin V.V., Kolesov S.A., Sherstobitova O.V., 2019

Irina A. Umnyagina - Candidate of Medical Sciences, Director (e-mail: recept@nniigp.ru; tel.: +7 (831) 419-61-94; ORCID: http://orcid.org/0000-0002-9276-7043).

Tat'yana V. Blinova - Doctor of Medical Sciences, Leading researcher at the Clinical Department (e-mail: btvdn@yandex.ru; tel.: +7 (915) 944-38-75; ORCID: http://orcid.org/0000-0001-5254-9378).

Larisa A. Strakhova - Researcher at the Clinical Department (e-mail: recept@nniigp.ru; tel.: +7 (831) 419-61-94; ORCID: http://orcid.org/0000-0003-0672-6622).

Vyacheslav V. Troshin - Candidate of Medical Sciences, Head of the Clinical Department (e-mail: recept@nniigp.ru; tel.: +7 (831) 419-61-94; ORCID: http://orcid.org/0000-0002-7077-0014).

Sergei A. Kolesov - Candidate of Biological Sciences, Senior researcher at the Clinical Department (e-mail: recept@nniigp.ru; tel.: +7 (831) 419-61-94; ORCID: http://orcid.org/0000-0003-4379-0228).

Ol'ga V. Sherstobitova - Dermatovenerologist at the Consultancy Polyclinic (e-mail: recept@nniigp.ru; tel.: +7 (831) 419-61-94; ORCID: http://orcid.org/0000-0001-5090-5594). 
body grows old due to products damaged by free radicals. These products accumulate in body cells with time $[7,8]$. As a body grows older, metabolic disorders occur in it, it becomes more susceptible to various diseases, and a person suffers from more and more chronic diseases. It all leads to a decrease in anti-oxidant protection processes and to free radicals growth in a body [9]. Excessive free radicals accumulation in middle-aged and elderly people is unquestionable. But free radicals occurrence in younger people and subsequent age dynamics require explanation as there are certain related issues here: whether excessive free radicals always exert negative impacts on a body; how apparent OS is in practically healthy people; whether OS intensity in a specific individual is constant or it can change depending on a person's age, working conditions, or effects produced by various adverse occupational factors. When experts analyze risks of health disorders for people who have to work in adverse working conditions, they often face a question: can OS parameters serve as biomarkers of an effect produced by adverse occupational factors on a body resulting in functional and organic disorders? Similar issues arise as regards body antioxidant system. Over recent years, some research has been performed proving that free radicals, being signal molecules, perform significant regulatory functions in a body, and excess antioxidants that eliminate them can lead to a so called "antioxidant" stress [10-12].

Our research goal was to reveal peculiarities related to age dynamics of integral oxidative stress parameters and total antioxidant capacity of blood serum, and to assess their changes depending on impacts exerted by adverse occupational factors on a worker's body.

Data and methods. We examined 244 people who underwent a regular medical check-up at the consultancy polyclinic of Rospotrebnadzor's Nizhniy Novgorod Scientific Research Institute for Hygiene and Occupational Pathology. All the participants gave their voluntary informed consent to be examined and the examination results being published. The performed research didn't infringe on the examined people's rights and didn't endanger their well-being in accordance with the biological and medical ethics requirements fixed in the Helsinki Declaration of the World Medical Association (2000) and the Order by RF Public Healthcare Ministry No. 266 (dated June 19, 2003). We excluded people with chronic diseases in their acute state, as well as with inflammatory and oncologic diseases from our research.

The first stage in the research involved mass screening of parameters related to oxidative stress (OS) and total antioxidant capacity (AOC) of blood serum in all the examined people. Occupation and impacts exerted by occupational factors were not taken into account at this stage in the research. Having analyzed all the obtained results, we divided all the examined people into four age groups; the 1st group $(n+78)$ included young people aged 18-20 $(19.1 \pm 1.5)$; the 2 nd group $(n=84)$, young people aged 21-35 (26.5 \pm 7.5$)$; the 3rd group $(n=67)$, middle-aged people aged 36-59 $(46.6 \pm 9.5)$; the 4 th group $(n=15)$, elderly people aged 60 an older $(56.2 \pm 5.1)$.

At the second stage in the research we analyzed OS and AOC taking into account age of an examined person and impacts exerted by adverse occupational factors $(n=174)$. Depending on impacts exerted by an adverse occupational factor, all the examined people were divided into five groups; the 1 st $(n=33$, aged $18-20)$ and the 2 nd $(n=34$, aged 21-35) groups were made up of students attending higher educational establishments and doing cyclic sports; the 3rd group $(n=52$, aged 21-35) were workers employed at a metallurgic plant that manufactured pipes; the 4th group $(n=29$, aged 36-65) included workers employed at a metallurgic plant and by a water supply organization; the 5th group $(n=26$, aged 36-65) were workers employed at chemical and bacteriological laboratories. We considered the 
following adverse factors in our research: physical overloads (the 1st, 2nd, and 4th groups) and chemical factors (exposure to formaldehyde, metals aerosols, acrylic polymers, phenol, acids, metals, chlorine, and disinfectants) (the 3rd and 5th groups). Working places and occupational factors were assessed and working conditions categories were established by in-house laboratories of a metallurgic plant and water supply organization according to the Federal Law FZ-426 issued on December 28, 2013 «On specialized assessment of working conditions». According to the above-mentioned assessment, chemicals factors at working places didn't exceed MPC. We assessed physical overloads for students who did cyclic sports as per their heart rate [13].

We determined integral parameters of OS and total AOC with reagent kits «PerOx (TOS/TOC) Kit» and «ImAnOx (TAS/TAC) Kit» manufactured by «Immundiagnostik» (Germany). OS was estimated as per peroxides occurrence in blood serum and was given in $\mu \mathrm{mol} / 1$ of peroxide that was present in a sample. To assess OS intensity in blood serum, we applied values recommended by reagent kits manufacturers; a value lower than $180 \mu \mathrm{mol} / 1$ meant OS was low; $180-310$ $\mu \mathrm{mol} / 1$, average OS: more than $310 \mu \mathrm{mol} / 1$, high OS. AOC was given in $\mu$ mol of exogenous peroxides decayed by antioxidants per 1 liter of blood serum. To assess AOC, we applied values recommended by reagent kits manufacturers; a value lower than $280 \mu \mathrm{mol} / 1$ meant AOC was low; 280-320 $\mu \mathrm{mol} / \mathrm{l}$, average AOC; more than $320 \mu \mathrm{mol} / \mathrm{l}$, high AOC. Blood was taken from the median cubical vein, and all the samples were treated immediately; blood serum was obtained with conventional techniques and stored at minus $80^{\circ} \mathrm{C}$ until it was analyzed.

We processed the results statistically with «AtteStat» software package. We applied non-parametric statistics methods for parameters with their distribution deviating from the standards one. The data were given as median, 25\%- and 75\%-quartiles (Med \pm IQR (25\%-75\%)). Validity of discrepancies between groups was calculated with MannWhitney test. If parameters distribution was standard, the data were given as simple mean $(\mathrm{M}) \pm$ standard deviation $(\sigma)$, and validity was assessed with Student's test. Critical significance of the results was fixed at $p<0.05$.

Results and discussion. We analyzed results of screening examinations and revealed that $\mathrm{OS}$ and $\mathrm{AOC}$ in the examined people were age-dependent. The data are given in the Table 1 .

Table 1

Os and AOC levels frequency and their quantitative characteristics in people from different age groups

\begin{tabular}{|l|c|c|c|c|}
\hline \multirow{2}{*}{ Parameters } & \multicolumn{4}{|c|}{ Age groups } \\
\cline { 2 - 5 } & 1 & 2 & 3 & 4 \\
\cline { 2 - 5 } & $18-20(n=78)$ & $21-35(n=84)$ & $36-59(n=67)$ & 60 and older $(n=15)$ \\
\hline OS and AOC levels & \multicolumn{4}{|c|}{ OS \% / AOC \% } \\
\hline Low & $60.2 / 10.3$ & $34.5 / 10.7$ & $28.4 / 35.2$ & $20.0 / 40.0$ \\
\hline Average & $24.4 / 41.0$ & $25.0 / 31.1$ & $17.9 / 47.8$ & $26.7 / 46.7$ \\
\hline High & $15.4 / 48.7$ & $40.5 / 58.2$ & $53.7 / 17.0$ & $53.3 / 13.3$ \\
\hline Med \pm IQR (25\%-75\%) & \multicolumn{4}{|c|}{ OS $(\mu \mathrm{mol} / \mathrm{l}) / \mathrm{AOC}(\mu \mathrm{mol} / \mathrm{l})$} \\
\hline Med & $176.2 / 320.2$ & $289.0 / 348.5$ & $355.7 / 290.9$ & $394.1 / 280.0$ \\
\hline $25 \%$ & $114.9 / 298.8$ & $131.5 / 293.8$ & $178.0 / 274.4$ & $225.5 / 260.2$ \\
\hline $75 \%$ & $275.8 / 342.0$ & $403.0 / 368.9$ & $600.0 / 304.8$ & $630.9 / 300.0$ \\
\hline $\mathrm{p}$ & \multicolumn{4}{|c|}{$\mathrm{p}_{1,2}=0.006 ; \mathrm{p}_{2,3}=0.009 ; \mathrm{p}_{1,3}=0.00036 ; \mathrm{p}_{3,4}=0.331}$. \\
& $\mathrm{p}^{*}{ }_{1,2}=0.213 ; \mathrm{p}_{2,3}=0.00015 ; \mathrm{p}_{1,3}^{*}=0.00022 ; \mathrm{p}_{3,4}=0.072 ; \mathrm{p}_{2,4}=0.003 ; \mathrm{p}_{1,4}=0.001$. \\
\hline
\end{tabular}

Note: $\mathrm{p}$ is validity of discrepancies in Med $(\mu \mathrm{mol} / \mathrm{l})$ OS between different age groups; $\mathrm{p}^{*}$ is validity of discrepancies in Med $(\mu \mathrm{mol} / \mathrm{l})$ AOC between different age groups. 
Table 2

OS and AOC levels frequency their quantitative characteristics in people from different age groups who are exposed to adverse occupational factors

\begin{tabular}{|c|c|c|c|c|c|}
\hline \multirow{4}{*}{ Parameters } & \multicolumn{5}{|c|}{ Age / Groups / Occupational factors } \\
\hline & \multicolumn{2}{|c|}{$18-20$} & $21-35$ & \multicolumn{2}{|c|}{$36-65$} \\
\hline & 1 & 2 & 3 & 4 & 5 \\
\hline & $\begin{array}{c}\text { Physical } \\
\text { overloads } \\
n=33\end{array}$ & $\begin{array}{c}\text { Physical } \\
\text { overloads } \\
n=34\end{array}$ & $\begin{array}{c}\text { Chemical } \\
\text { factor } \\
n=52\end{array}$ & $\begin{array}{c}\text { Physical } \\
\text { overloads } \\
n=29\end{array}$ & $\begin{array}{c}\text { Chemical } \\
\text { factor } \\
n=26\end{array}$ \\
\hline OS and AOC levels & \multicolumn{5}{|c|}{ OS \% / AOS \% } \\
\hline Low & $78.8 / 9.1$ & $50.0 / 5.9$ & $28.8 / 5.8$ & $31.0 / 27.5$ & $7.7 / 42.3$ \\
\hline Average & $15.2 / 24.2$ & $11.8 / 20.6$ & $21.2 / 11.5$ & $41.4 / 48.3$ & $15.4 / 42.3$ \\
\hline High & $6.0 / 66.7$ & $38.2 / 73.5$ & $50.0 / 82.7$ & $27.6 / 24.2$ & $76.9 / 15.4$ \\
\hline Med \pm IQR $(25-75 \%)$ & \multicolumn{5}{|c|}{ OS $(\mu \mathrm{mol} / \mathrm{l}) / \mathrm{AOC}(\mu \mathrm{mol} / \mathrm{l})$} \\
\hline Med & $107.8 / 341.0$ & $200.8 / 336.7$ & $360.0 / 360.0$ & $252.0 / 294.3$ & $540.0 / 283.7$ \\
\hline $25 \%$ & $56.4 / 320.0$ & $97.9 / 319.6$ & $192.3 / 327.0$ & $107.2 / 277.9$ & $414.1 / 248.7$ \\
\hline $75 \%$ & $138.0 / 385.0$ & $321.8 / 347.9$ & $412.0 / 360.0$ & $310.0 / 317.1$ & $733.3 / 302.7$ \\
\hline $\mathrm{p}$ & \multicolumn{5}{|c|}{$\begin{aligned} \mathrm{p}_{1,2} & =0.0006 ; \mathrm{p}_{2,3}=0.009 ; \mathrm{p}_{2,4}=0.001 ; \mathrm{p}_{4,5}=0.0009 \\
\mathrm{p}^{*}=0.2 & =0.382 ; \mathrm{p}_{2,3}^{*}=0.351 ; \mathrm{p}^{*}{ }_{2,4}=0.033 ; \mathrm{p}_{4,5}^{*}=0.034\end{aligned}$} \\
\hline
\end{tabular}

Note: $\mathrm{p}$ is validity of discrepancies in Med $(\mu \mathrm{mol} / \mathrm{l})$ OS between different age groups and occupational factors; $\mathrm{p}^{*}$ is validity of discrepancies in Med $(\mu \mathrm{mol} / \mathrm{l})$ AOC between different age groups and occupational factors

The obtained results show that peroxides formation intensified with age and it proved that OS grew. Changes to a greater extent were related to high and low OS. We should note that most younger people tended to have low OS as high OS was met 4 times less frequently among them. But a share of people with high OS started to grow among those aged 21 and older, by $25.1 \%$ in the 2 nd group, and by $13.2 \%$ in the 3 rd group against previous groups. A share of people with low OS in groups $2-4$ decreased by $25.7 \%, 6.1 \%$ and $8.4 \%$ respectively. Peroxides contents in blood serum grew in people who were younger than $59 \quad\left(\mathrm{p}_{1,2}=0.006 ; \mathrm{p}_{2,3}=0.009\right.$; $\left.\mathrm{p}_{1,3}=0.00036\right)$ and didn't change in the following years $\left(\mathrm{p}_{3,4}=0.331\right)$. Average OS frequency didn't depend on age and a share of people with average OS varied from 17.9 to $26.7 \%$.

Changes in AOC were oppositely directed. High and average AOC prevailed among young people and low AOC was detected only in $10 \%$ people from this age group. Decayed peroxides contents in blood serum didn't differ authentically in the $1 \mathrm{st}$ and 2 nd groups $\left(\mathrm{p}^{*}{ }_{1,2}=0.213\right)$. Low and average AOC prevailed among people from the 3rd and 4th groups and high AOC was detected only in $13-17 \%$ of the examined people from these groups. Decayed peroxides contents in blood serum didn't differ authentically in these groups $\left(\mathrm{p}_{3,4}=0.072\right)$. AOC parameters in middle-aged and elderly people were different from those detected in young people $\left(\mathrm{p}_{2,3}=0.00015 ; \mathrm{p}_{1,3}=0.00022\right.$; $\left.\mathrm{p}^{*}{ }_{2,4}=0.003 ; \mathrm{p}^{*}{ }_{1,4}=0.001\right)$. Average AOC frequency didn't depend on age and varied from 31.1 to $47.8 \%$.

Table 2 contain $s$ the results of changes in OS and AOC parameters in people from different age groups who are exposed to adverse occupational factors.

The obtained results show that impacts exerted by both physical overloads and chemical factors became greater with age and led to higher OS and lower AOC. People who were exposed to chemical factors had authentically higher OS than people from the same age group who had to face physical overloads. This discrepancy was the most apparent among people aged 36-65 (the 4th 
and the 5th groups, $\left.\mathrm{p}_{4,5}=0.0009\right)$. Younger people (aged 18-20) who faced physical overloads at their workplaces had 2 times lower peroxides contents in their blood serum than young people aged 21-35 (the 1st and the 2 nd groups, $\left.\mathrm{p}_{1,2}=0.0006\right)$. Changes in AOC were less dependent on physical overloads and chemical factors among people from the 1st, 2nd, and 3rd groups as AOC remained stably high regardless of any occupational factors. Discrepancies were detected among middle-aged and elderly people and chemical factors had greater adverse effects on AOC than physical overloads $\left(\mathrm{p}_{4,5}=0.034\right)$. Physical overloads at older age promoted more apparent decrease in AOC against parameters detected among young people $\left(\mathrm{p}_{2,4}=0.033\right)$.

Our research revealed that peroxides contents in blood serum increased and total AOC went down with age. It indicated that OS grew and antioxidant protection decreased. We detected age-related dynamics of integral OS and AOC parameters and determined their values for each age group. Low OS and high / average AOC prevailed among younger people. Negative changes in OS and AOC grew in people older than 20, the trend continued up to age of 59 and then the parameters remained stable in most of the examined people. The obtained results on increased OS in elderly people are consistent with literature. Thus, Edrey and Salmon think than ageing involves a decrease in adaptive mechanisms, antioxidant and detoxification reserves of a body that are able to resist high OS [14]. Even if an elderly person consumes antioxidant micronutrients, it often doesn't produce any positive effects [15]. Excess peroxides quantities were revealed even in practically healthy people aged 18-20 and 21-35. Peroxides contents in blood serum varied from 436.2 to $733.7 \mu \mathrm{mol} / 1$ and AOC was high, from 350.0 to $386.5 \mu \mathrm{mol} / 1$. In this case an increase in OS can have a positive regulatory effect aimed at activating antioxidant protection processes. Some researchers showed that lipid peroxidation products caused an adaptive response and increased tolerance to future oxidative stress thus enhancing protective capacities of a body $[16,17]$. A share of people with increased OS parameters went up among people from older age groups. Some researchers believe that disorders in the system of free radical oxidation and antioxidant protection are a significant pathogenetic component in development of various pathologies and these parameters can be a risk factor that causes this development. Therefore young people should have regular medical checkups aimed at determining free radicals occurrence and antioxidant protection parameters. Should there be any negative changes, a person has to undergo a more profound medical examination, pay greater attention to his or her work and rest regime and nutrition. Should there be any persistent disorders in antioxidant protection, a physician might prescribe medications or biologically active food additives in order to increase resistance to OS and enhance antioxidant protection of a body.

Our research revealed different changes in OS depending on exposure to an adverse factor in different age groups. Physical overloads tend to have greater adverse effects on free radical oxidation system with age. Young people aged 18-20 and 21-36 are more resistant to oxidative stress under physical overloads. High AOC prevailed among people from these age groups. Our research results indicate that within the same age group OS is more apparent in people who are exposed to chemical factors than in those who have to face physical overloads at their workplace. Obviously it is due to a body getting gradually adapted to physical loads. Similar adaptation to a chemical factor never occurs. Constant exposure to chemicals, even if their concentrations in a working area don't exceed MPC, exerts negative impacts on metabolism, organs, and systems in a body. Workers employed at a metallurgic plant and those who deal with water supply and treatment are exposed to chemical 
factors that can cause OS and damage antioxidant protection of a body. Experimental toxicological research revealed that multiple chemical environmental factors (nitrogen oxide, sulfur dioxide, formaldehyde, cigarette smoke etc.) can cause free radicals formation and it results in OS and damage to DNA, proteins, and lipids, mutagenicity and anti-inflammation factors stimulation [18, 19]. Besides, ecological contaminants in the environment can act at the molecular level and damage any molecules (for example, polyunsaturated fat acids, glutathione, antioxidant enzymes, and some aminoacids) and it can lead to a decrease in antioxidant protection against free radicals [20]. When water is chlorinated, hypochlorous acid occurs in the process; this substance is highly reactive and causes singlet oxygen formation and greater OS. Redox metals (iron, copper, chrome, cobalt, and others) that occur in water can have negative effects on mitochondrial membranes, produce free radicals, cause OS and inhibit antioxidant protection [21].

Conclusions. So, our research allowed to determine age-related dynamics of integral OS and AOC parameters and their val- ues for each age group, to differentiate dependence of changes in them on a type of an adverse occupational factor in different age groups. We can assume that colorimetric techniques for integral $\mathrm{OS}$ and $\mathrm{AOC}$ assessment and gradation of their level that we applied in our work give a relevant picture of OS and AOC intensity depending on age and impacts exerted by adverse occupational factors. These parameters can be applied in practical healthcare as routine biochemical tests aimed at assessing oxidationantioxidation system; we recommend to apply them for analyzing risks related to a worker's body being exposed to adverse occupational factors, both physical and chemical ones. They can also serve as informative tests for monitoring over health, assessing gravity of a disease and forecasting its course, as well as assessing treatment efficiency and preventive activities implementation.

Funding. The research was not granted any sponsor support.

Conflict of interests. The authors state there is no any conflict of interests.

\section{References}

1. Martusevich A.K., Karuzin K.A. Oksidativnyi stress i ego rol' v formirovanii dizadaptatsii i patologii [Oxidative stress and its role in the formation of disadaptation and pathology]. Bioradikaly i antioksidanty, 2015, vol. 2, no. 2, pp. 5-18 (in Russian).

2. Rosales-Corral S., Tan D.-X., Manchester L., Reiter R.J. Diabetes and Alzheimer Diseasetwo overlapping pathologies with the same background: Oxidative Stress. Oxidative Medicine and Cellular Longevity, 2015, 14 p. Available at: https://www.hindawi.com/journals/omcl/2015/985845/ (26.09.2018). DOI: 10.1155/2015/985845.

3. Soazig L.L., Gilles S., Martinez M.C., Ramaroson A. Oxidative Stress and Metabolic Pathologies: From an Adipocentric Point of View. Oxidative Medicine and Cellular Longevity, 2014, no. 2014,18 p. DOI: $10.1155 / 2014 / 908539$

4. Pavlyuchenko I.I., Dydyshko E.I., Okhremenko O.S. Comparative analysis of the dynamics of the immune-antioxidant status of the pro-antioxidant system in patients with thyroid. Kubanskii nauchnyi meditsinskii vestnik, 2017, no. 5, pp. 59-62 (in Russian). DOI: 10.25207/1608-6228-201724-5-59-62

5. Rakhmanov R.S., Blinova T.V., Kolesov S.A., Strakhova L.A., Troshin V.V., Umnyagina I.A., Sapozhnikova M.A. Evaluation of prognostic significance of functional and biochemical indices for health status assessment in young person's working in tube-casting plants. Kubanskii nauchnyi meditsinskii vestnik, 2017, no. 2, pp. 123-128 (in Russian). DOI: 10.25207/1608-62282017-2-123-128 
6. Hawley B., L'Orange C., Olsen D.B., Marchese A.J., Volckens J. Oxidative stress and aromatic hydrocarbon response of human bronchial epithelial cells exposed to petro- or biodiesel exhaust treated with a diesel particulate filter. Toxicological Sciences, 2014, vol. 141, no. 2, pp. 505-514. Available at: https://academic.oup.com/toxsci/article/141/2/505/2511607 (26.09.2018). DOI: $10.1093 /$ toxsci/kfu147

7. Go Y.-M., Jones D.P. Redox theory of aging: implications for health and disease. Clin Sci (London), 2017, vol. 131, no. 14, pp. 1669-1688. Available at: https://www.ncbi.nlm.nih.gov/pmc/articles/PMC5773128/ (24.09.2018). DOI: 10.1042/CS20160897

8. Dues D.J., Andrews E.K., Schaar C.E., Bergsma A.L., Senchuk M.M., Van Raamsdonk J.M. Aging causes decreased resistance to multiple stresses and a failure to activate specific stress response pathways. Aging (Albany N.Y.), 2016, vol. 8, no. 4, pp. 777-795. DOI: 10.18632/aging.100939

9. Kim J.Y., Kim O.Y., Paik J.K., Kwon D.Y., Kim H.-J., Lee J.H. Association of age-related changes in circulating intermediary lipid metabolites, inflammatory and oxidative stress markers, and arterial stiffness in middle-aged men. Age (Dordrecht, Netherlands), 2013, vol. 35, no. 4, pp. 1507-1519. DOI: $10.1007 / \mathrm{s} 11357-012-9454-2$

10. Urbański K., Nowak M., Guzik T.J. Oxidative stress and vascular function. Postepy Biochem, 2013, vol. 59, no. 4, pp. 424-31. DOI: 10.1093/annhyg/mev024

11. Sayin V.I., Ibrahim M.X., Larsson E., Nilsson J.A., Lindahl P., Bergo M.O. Antioxidants accelerate lung cancer progression in mice. Science Translational Medicine, 2014, vol. 6, no. 221, pp. 221-225. DOI: 10.1126/scitranslmed.3007653

12. Van'ek K. Antioksidanty: khoroshie, plokhie, zlye [Antioxidants: good, bad, evil]. Shkola zdorov'ya Titovykh, 2017. Available at: https://articles.shkola-zdorovia.ru/antioksidanty-horoshieplohie-zlye-kristofer-vanek/ (26.09.2018) (in Russian).

13. Valeev G.G. Sposob opredeleniya stepeni peregruzki serdtsa [Method for detecting the degree of cardiac overloading]. FindPatent.RU, 2007. Available at: https://findpatent.ru/patent/230/2306846.html (25.08.2018) (in Russian).

14. Edrey Y.H., Salmon A.B. Revisiting an age-old question regarding oxidative stress. Free Radic Biol. Med., 2014, vol. 71, pp. 368-378.

15. Phillips C. Lifestyle modulators of neuroplasticity: how physical activity, mental engagement, and diet promote cognitive health during aging. Neural Plast, 2017, pp. 3589271. Available at: https://www.ncbi.nlm.nih.gov/pmc/articles/PMC5485368/ (13.08.2018). DOI: 10.1155/2017/3589271

16. European contribution to the study of ROS: A summary of the findings and prospects for the future from the COST action BM1203 (EU-ROS). Redox Biology, 2017, no. 13, pp. 94-162. Available at: https://www.ncbi.nlm.nih.gov/pmc/articles/PMC5975209/ (28.09.2018). DOI: 10.1016/ j.redox.2017.05.007

17. De Gonzalo-Calvo D., De Luxán-Delgado B., Rodríguez-González S., García-Macia M., Suárez F.M., Solano J.J., Rodríguez-Colunga M.J., Coto-Montes A. Oxidative protein damage is associated with severe functional dependence among the elderly population: a principal component analysis approach. Journals of Gerontology-Series a Biological Sciences and Medical Sciences, 2012, vol. 67, no. 6, pp. 663-670. DOI: 10.1093/gerona/glr215

18. Spagnolo A.M., Ottria G., Perdelli F., Cristina M.L. Chemical characterisation of the coarse and fine particulate matter in the environment of an underground railway system: cytotoxic effects and oxidative stress - a preliminary study. Int J. Environ. Res. Public. Health, 2015, vol. 12, no. 4, pp. 4031-4046. Available at: https://www.ncbi.nlm.nih.gov/pmc/articles/PMC4410231/ (24.09.2018). DOI: 10.3390/ijerph120404031

19. Pomierny B., Krzyżanowska W., Smaga I., Pomierny-Chamioło L., Stankowicz P., Budziszewska B. Ethylene Glycol Ethers Induce Oxidative Stress in the Rat Brain. Neurotox Res, 2014, vol. 26, no. 4, pp. 422-429. DOI: 10.1007/s12640-014-9486-8

20. Poljšakand B., Fink R. The Protective Role of Antioxidants in the Defence against ROS/RNS-Mediated Environmental Pollution. Oxid Med Cell Longev, 2014, pp. 671539. DOI: 10.1155/2014/671539 
21. Pizzino G., Irrera N., Cucinotta M., Pallio G., Mannino F., Arcoraci V., Squadrito F., Altavilla D., Bitto A. Oxidative Stress: Harms and Benefits for Human Health. Oxid Med Cell Longev, 2017, pp. 8416763. Available at: https://www.ncbi.nlm.nih.gov/pmc/articles/PMC5551541/ (01.06.2018). DOI: $10.1155 / 2017 / 8416763$

Umnyagina I.A., Blinova T.V., Strakhova L.A., Troshin V.V., Kolesov S.A., Sherstobitova O.V. Oxidative stress and antioxidant protection in people of various age under contact with adverse occupational factors. Health Risk Analysis, 2019, no. 3, pp. 104-111. DOI: 10.21668/health.risk/2019.3.12.eng

Received: 02.10 .2019

Accepted: 26.07.2019

Published: 30.09.2019 